\title{
In memory of
}

Keith John Jeffery (1952-2016)

and

John David Milner (1949-2016) 
'Listen, Kolya, among other things, you are going to be very unhappy in life', Alyosha said ... 'But even so, life on the whole you will bless.'

Dostoyevsky, The Brothers Karamazov

A man's fairest memorial is still his own portrait.

Goethe 